\title{
Isomorphous Substitution in Bimetallic Oxide Clusters
}

\author{
E. Janssens, ${ }^{1,2, *}$ G. Santambrogio, ${ }^{1}$ M. Brümmer, ${ }^{1}$ L. Wöste,,${ }^{1}$ P. Lievens, ${ }^{2}$ J. Sauer,${ }^{3, \dagger}$ G. Meijer, ${ }^{4}$ and K. R. Asmis ${ }^{4, \ddagger}$ \\ ${ }^{1}$ Institut für Experimentalphysik, Freie Universität Berlin, Arnimallee 14, D-14195 Berlin, Germany \\ ${ }^{2}$ Laboratorium voor Vaste-Stoffysica en Magnetisme, Katholieke Universiteit Leuven, Celestijnenlaan 200D, B-3001 Leuven, Belgium \\ ${ }^{3}$ Institut für Chemie, Humboldt-Universität Berlin, Unter den Linden 6, D-10099 Berlin, Germany \\ ${ }^{4}$ Fritz-Haber-Institut der Max-Planck-Gesellschaft, Faradayweg 4-6, D-14195 Berlin, Germany
}

(Received 30 December 2005; published 14 June 2006)

\begin{abstract}
The geometric and electronic structure of bimetallic oxide clusters is studied as a function of their composition with gas phase vibrational spectroscopy. Infrared multiple photon dissociation spectra of titanium-vanadium oxide cluster anions are measured in the 500 to 1200 wave number range and assigned on the basis of harmonic frequencies calculated using density functional theory. Singly substituted $\left(\mathrm{V}_{2} \mathrm{O}_{5}\right)_{n-1}\left(\mathrm{VTiO}_{5}\right)^{-}(n=2-4)$ cluster anions are shown to form polyhedral caged structures similar to those predicted for their isoelectronic counterparts, the neutral $\left(\mathrm{V}_{2} \mathrm{O}_{5}\right)_{n}$ clusters. Upon systematic exchange of $\mathrm{V}$ by Ti atoms in $\mathrm{V}_{4-n} \mathrm{Ti}_{n} \mathrm{O}_{10}^{-}(n=1-4)$, the structure does not change. The stress induced by the isomorphous substitution results in an increased number of unpaired electrons $(n-1)$ for the Ti-rich systems, leading to a quartet ground state for $\mathrm{Ti}_{4} \mathrm{O}_{10}^{-}$.
\end{abstract}

DOI: 10.1103/PhysRevLett.96.233401

PACS numbers: 36.40.Mr, 31.15.Ew

The size- and composition-dependent properties of gas phase transition metal oxide clusters are intensely studied, for example, to aid in the design of functional building blocks for nanostructured materials [1] and to gain a better understanding of the elementary steps in heterogeneous catalysis [2]. A long sought-after goal, in this regard, has been the tailoring of the electronic and geometric structure of clusters by carefully choosing the cluster composition. This approach has been limited up to now by both the availability of adequate cluster sources as well as structuresensitive characterization techniques.

Recently, photodissociation spectroscopy [3-6] as well as resonance-enhanced multiple photon ionization [7-9] combined with radiation from a tunable infrared free electron laser have proven very useful in probing the structure of monometallic oxide clusters as a function of the cluster size. Here, we present the first systematic compositiondependent infrared study of bimetallic oxide clusters in the gas phase. The structures of titanium-vanadium oxide cluster anions are characterized by infrared multiple photon photodissociation (IRMPD) in combination with density functional theory (DFT) calculations. By sequentially exchanging V with Ti atoms we exploit the control over the clusters composition to investigate its influence on the electronic and geometric structure. Previously, IRMPD studies demonstrated that negatively charged $\left(\mathrm{V}_{2} \mathrm{O}_{5}\right)_{n}^{-}$ clusters $(n=2-4)$ form polyhedral cages made of $(-\mathrm{O})_{3} \mathrm{~V}=\mathrm{O}$ units [4]. Opposite to the neutral $\left(\mathrm{V}_{2} \mathrm{O}_{5}\right)_{n}$ cages [10], the anionic clusters are open shell systems; they have one unpaired electron in vanadium $d$ states. While the unpaired electron is fully delocalized over all $\mathrm{V}$ atoms in $n=2$, it localizes on a single atom for the larger clusters [4]. Here we extend this study in two series of experiments. First, a single $\mathrm{V}$ atom is replaced by a $\mathrm{Ti}$ atom, yielding closed-shell $\left(\mathrm{V}_{2} \mathrm{O}_{5}\right)_{n-1}\left(\mathrm{VTiO}_{5}\right)^{-}$anions isoelectronic with the neutral $\left(\mathrm{V}_{2} \mathrm{O}_{5}\right)_{n}$ clusters. Second, the number of atoms is kept constant, but each $\mathrm{V}$ atom in $\mathrm{V}_{4} \mathrm{O}_{10}^{-}$is sequentially exchanged by a Ti atom, i.e., a stepwise removal of valence electrons. For both series the geometric and electronic structures are determined from the IRMPD spectra in combination with DFT calculations. It will be shown that the $\mathrm{V}$ by Ti substitution in the considered clusters results in a modified electronic structure while the cluster morphology remains unaltered.

The vanadium-titanium oxide cluster anions are produced in a $10 \mathrm{~Hz}$ dual laser vaporization source $[11,12]$, coupled to a tandem mass spectrometer-ion trap system described in Ref. [5]. The helium gas contains $1 \%$ of $\mathrm{O}_{2}$, yielding oxygen saturated cluster growth conditions. The anion beam is collimated and mass-selected by a first quadrupole mass filter. Mass-selected cluster anions are accumulated in a linear radio-frequency 16-pole ion trap and collisionally cooled to the trap housing temperature $(17 \mathrm{~K})$ mediated by a helium buffer gas. IRMPD spectra of the trapped cold ions are obtained after multiple photon excitation and subsequent monitoring of the fragment ion yield with a second quadrupole mass filter and a channeltron detector.

The IR light source used is the Free Electron Laser for Infrared eXperiments (FELIX) [13] located in Nieuwegein, The Netherlands. In the present work FELIX is used at a repetition rate of $5 \mathrm{~Hz}$ in the 500 to $1200 \mathrm{~cm}^{-1}$ range. When FELIX is resonant with an IR allowed transition, multiple photon absorption can take place. The cluster is excited resonantly over discrete states into the quasicontinuum. It then continues to absorb photons, but this energy is quickly randomized among all vibrational degrees of freedom. Once the internal energy reaches the dissociation limit the molecule may fragment [14].

Mass spectra of $\mathrm{V}_{n} \mathrm{O}_{p}^{-}, \mathrm{Ti}_{m} \mathrm{O}_{p}^{-}$and $\mathrm{V}_{n} \mathrm{Ti}_{m} \mathrm{O}_{p}^{-}$cluster anions, produced under similar conditions, are shown in Fig. 1. The mass peaks of $\mathrm{Ti}_{m} \mathrm{O}_{p}^{-}$are broadened due to the 


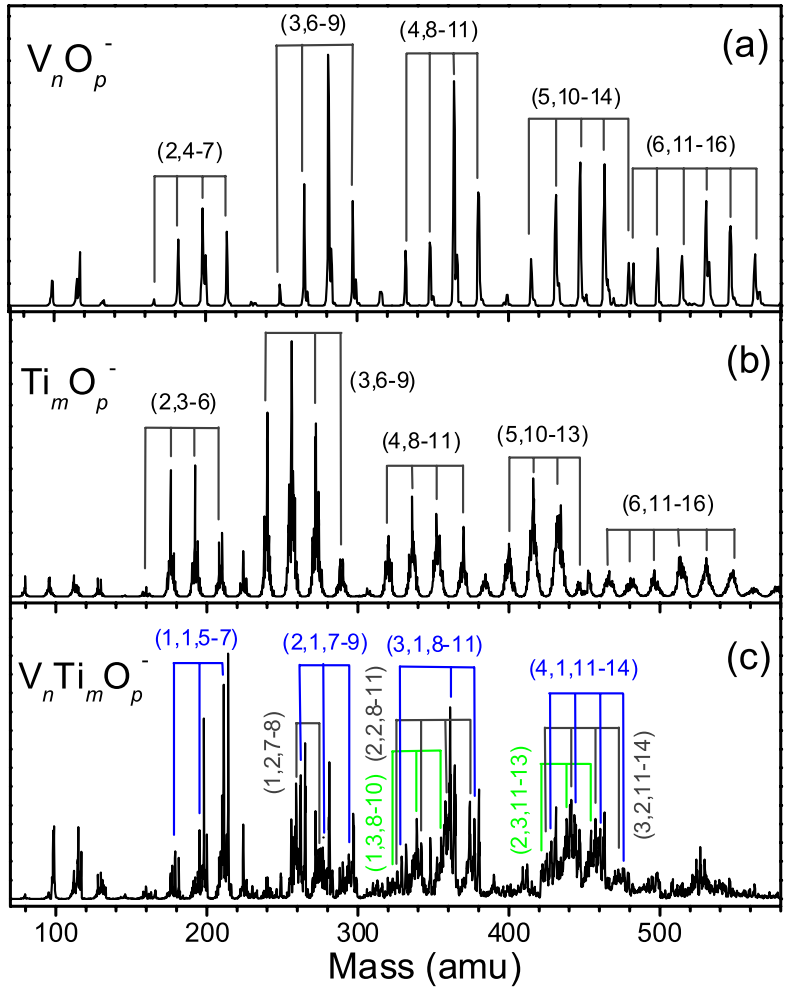

FIG. 1 (color online). Mass spectra of pure metal oxide (a) $\mathrm{V}_{n} \mathrm{O}_{p}^{-}$, (b) $\mathrm{Ti}_{m} \mathrm{O}_{p}^{-}$, and (c) bimetallic oxide $\mathrm{V}_{n} \mathrm{Ti}_{m} \mathrm{O}_{p}^{-}$clusters. In (c), for clarity only, a selection of peaks is labeled with $(n, m, p)$.

isotope distribution of Ti. Note that the masses of the most abundant isotope of $\mathrm{Ti}$ and $\mathrm{O}_{3}$ are equal. A consistent assignment of the mass peaks starting from the small clusters and following the observed progression is possible and indicated by the labels in Fig. 1. The overall distributions of $\mathrm{V}_{n} \mathrm{O}_{p}^{-}$and $\mathrm{Ti}_{m} \mathrm{O}_{p}^{-}$are alike and similar to those observed before [4,15-17]. Investigations on neutral clusters using postionization, however, give a lower oxygen to metal ratio $[9,18]$, most probably because of the higher ionization potential of highly oxidized clusters [17].

The mass spectrum of the bimetallic oxide clusters is considerably more complex, since many $(n, m, p)$ combinations are possible. Source conditions were tuned to maximize the signal of the cluster composition under investigation. The IRMPD experiments are carried out on the corresponding ${ }^{48} \mathrm{Ti}$ containing isotopomers. A fit of a $\mathrm{V}_{4-n} \mathrm{Ti}_{n} \mathrm{O}_{10}^{-}(n=1-4)$ distribution, taking into account the natural isotope patterns, to the measured mass spectrum in the 348-366 amu region shows that the presence of other compositions in the selected mass channels is negligible except for the $355 \mathrm{amu}$ mass peak $\left(\mathrm{VTi}_{3} \mathrm{O}_{10}^{-}\right)$, where there is a $10 \%$ contamination of $\mathrm{Ti}_{4} \mathrm{O}_{10}^{-}$. An extended analysis of the mass spectra can be found in the supplementary information [19].

We performed IRMPD experiments on two cluster series. First, we studied the influence of substituting a single $\mathrm{V}$ atom by a Ti atom for $\left(\mathrm{V}_{2} \mathrm{O}_{5}\right)_{n-1}\left(\mathrm{VTiO}_{5}\right)^{-}(n=2-4)$.
Then we examined the effect of the sequential replacement of $\mathrm{V}$ by Ti in $\mathrm{V}_{4-n} \mathrm{Ti}_{n} \mathrm{O}_{10}^{-}(n=1-4)$ anions. The observed fragmentation channels are listed in Table I. Note that different clusters can yield the same fragment, implying that double mass selection is imperative for these measurements. IRMPD spectra of bimetallic vanadium-titanium oxide anions are shown in the top panel of Fig. 2. The spectra are obtained by monitoring the fragment ion denoted with an asterisk in Table I.

The dissociation upon IR irradiation of $\mathrm{V}_{3} \mathrm{TiO}_{10}^{-}$, $\mathrm{V}_{5} \mathrm{TiO}_{15}^{-}$, and $\mathrm{V}_{7} \mathrm{TiO}_{20}^{-}$is governed by the formation of two closed-shell fragments. All three species form $\mathrm{V}_{3} \mathrm{O}_{8}^{-}$, but the two larger anions prefer to dissociate into $\mathrm{V}_{3} \mathrm{TiO}_{10}^{-}$. The IRMPD spectra of the $\left(\mathrm{V}_{2} \mathrm{O}_{5}\right)_{n-1}\left(\mathrm{VTiO}_{5}\right)^{-}(n=2-4)$ series are characterized by three absorption regions: (i) a sharp peak around $1000 \mathrm{~cm}^{-1}$, (ii) a broad and intense band in the $800-950 \mathrm{~cm}^{-1}$ region, and a weaker absorption band around $700 \mathrm{~cm}^{-1}$.

To assist the structural assignment DFT geometry optimizations of $\left(\mathrm{V}_{2} \mathrm{O}_{5}\right)_{n-1}\left(\mathrm{VTiO}_{5}\right)^{-} \quad(n=2-4)$ and $\mathrm{V}_{4-n} \mathrm{Ti}_{n} \mathrm{O}_{10}^{-}(n=1-4)$ clusters were carried out with the TURBOMOLE program [20], employing the B3LYP hybrid functional [21] and the TZVP basis sets [22]. Harmonic vibrational frequencies are obtained from second analytic derivatives [23] and were scaled using a 0.9429 multiplication factor [6]. The calculated spectra are convoluted with a

TABLE I. Relative abundances of the IR fragmentation channels of $\mathrm{V}_{n} \mathrm{Ti}_{m} \mathrm{O}_{p}^{-}$. Species with formal vanadium $+V$ and titanium $+I V$ oxidation states are marked with $\dagger$. An $*$ denotes the fragment monitored in the IRMPD study. Fragments with a relative abundance lower than $10 \%$ are not given.

\begin{tabular}{cccc}
\hline \hline Cluster & $\begin{array}{c}\text { Fragment } \\
\text { ion }\end{array}$ & $\begin{array}{c}\text { Relative } \\
\text { abundance }(\%)\end{array}$ & $\begin{array}{c}\text { Lost } \\
\text { neutral }\end{array}$ \\
\hline$\dagger \mathrm{V}_{7} \mathrm{TiO}_{20}^{-}$ & $* \dagger \mathrm{V}_{3} \mathrm{TiO}_{10}^{-}$ & 100 & $\dagger \mathrm{V}_{4} \mathrm{O}_{10}$ \\
& $\dagger \mathrm{V}_{3} \mathrm{O}_{8}^{-}$ & 64 & $\dagger \mathrm{V}_{4} \mathrm{TiO}_{12}$ \\
$\dagger \mathrm{V}_{5} \mathrm{TiO}_{15}^{-}$ & $* \dagger \mathrm{V}_{3} \mathrm{TiO}_{10}^{-}$ & 100 & $\dagger \mathrm{V}_{2} \mathrm{O}_{5}$ \\
& $\dagger \mathrm{V}_{3} \mathrm{O}_{8}^{-}$ & 64 & $\dagger \mathrm{V}_{2} \mathrm{TiO}_{7}$ \\
$\dagger \mathrm{V}_{3} \mathrm{TiO}_{10}^{-}$ & $\mathrm{V}_{3} \mathrm{TiO}_{9}^{-}$ & 26 & $\mathrm{O}$ \\
& $* \dagger \mathrm{V}_{3} \mathrm{O}_{8}^{-}$ & 100 & $\dagger \mathrm{TiO}_{2}$ \\
& $\mathrm{~V}_{3} \mathrm{O}_{7}^{-}$ & 24 & $\mathrm{TiO}_{3}$ \\
& $\mathrm{~V}_{2} \mathrm{TiO}_{7}^{-}$ & 33 & $\mathrm{VO}_{3}$ \\
& $\dagger \mathrm{VO}_{3}^{-}$ & 12 & $\dagger \mathrm{V}_{2} \mathrm{TiO}_{7}$ \\
$\mathrm{~V}_{2} \mathrm{Ti}_{2} \mathrm{O}_{10}^{-}$ & $\mathrm{V}_{2} \mathrm{Ti}_{2} \mathrm{O}_{9}^{-}$ & 38 & $\mathrm{O}$ \\
& $* \dagger \mathrm{VTi}_{2} \mathrm{O}_{7}^{-}$ & 100 & $\mathrm{VO}_{3}$ \\
$\mathrm{VTi}_{3} \mathrm{O}_{10}^{-}$ & $\dagger \mathrm{VTi}_{3} \mathrm{O}_{9}^{-}$ & 100 & $\mathrm{O}$ \\
& $* \dagger \mathrm{VTi}_{2} \mathrm{O}_{7}^{-}$ & 46 & $\mathrm{TiO}_{3}$ \\
& $\mathrm{Ti}_{3} \mathrm{O}_{7}^{-}$ & 12 & $\mathrm{VO}_{3}$ \\
$\mathrm{Ti}_{4} \mathrm{O}_{10}^{-}$ & $\mathrm{Ti}_{4} \mathrm{O}_{9}^{-}$ & 96 & $\mathrm{O}$ \\
& $\mathrm{Ti}_{4} \mathrm{O}_{8}^{-}$ & 100 & $\mathrm{O}_{2}$ \\
& $* \mathrm{Ti}_{3} \mathrm{O}_{7}^{-}$ & 54 & $\mathrm{TiO}_{3}$ \\
\hline \hline
\end{tabular}




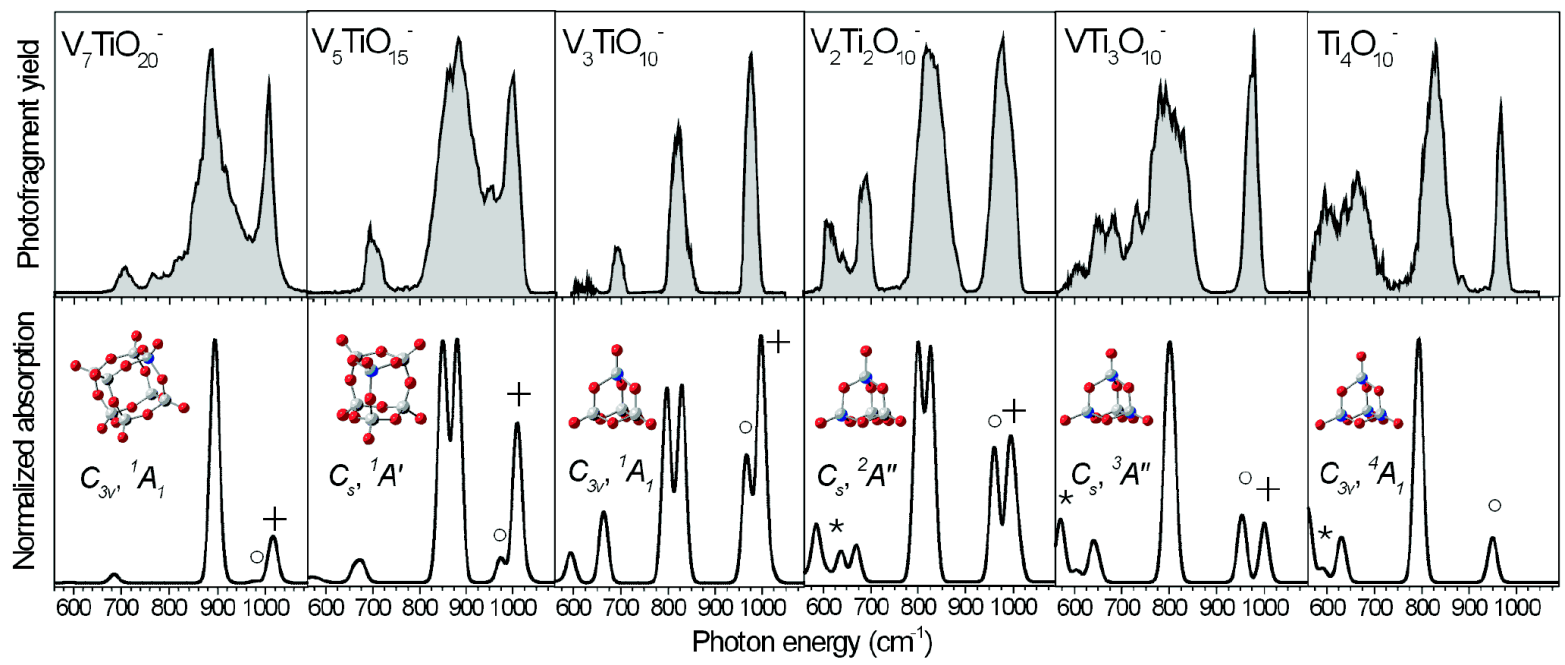

FIG. 2 (color online). Experimental IRMPD (top) and simulated IR spectra (bottom) of $\mathrm{V}_{7} \mathrm{TiO}_{20}^{-}, \mathrm{V}_{5} \mathrm{TiO}_{15}^{-}, \mathrm{V}_{3} \mathrm{TiO}_{10}^{-}, \mathrm{V}_{2} \mathrm{Ti}_{2} \mathrm{O}_{10}^{-}$, $\mathrm{VTi}_{3} \mathrm{O}_{10}^{-}$, and $\mathrm{Ti}_{4} \mathrm{O}_{10}^{-}$in the 560 to $1085 \mathrm{~cm}^{-1}$ range. The simulated spectra are based on scaled harmonic frequencies of the $\mathrm{B} 3 \mathrm{LYP} /$ TZVP optimized geometries. Stretches of $\mathrm{V}=\mathrm{O}, \mathrm{Ti}^{(-)}=\mathrm{O}$, and $\mathrm{Ti}-\mathrm{O} \cdot$ bonds are labeled with,$+ \mathrm{O}$, and $*$, respectively.

Gaussian line shape of $20 \mathrm{~cm}^{-1}$ FWHM (bottom panel of Fig. 2).

Polyhedral cage structures, in which each metal atom $M$ forms a single, terminal $M=\mathrm{O}$ double bond and takes part in three $M-\mathrm{O}-M$ single bond bridges, are found as lowest energy isomers for the closed-shell $\left(\mathrm{V}_{2} \mathrm{O}_{5}\right)_{n-1} \times$ $\left(\mathrm{VTiO}_{5}\right)^{-}(n=2-4)$ clusters. Their simulated infrared absorption spectra agree satisfactorily with the experimental IRMPD spectra, yielding the following assignment of the three absorption regions. The narrow bands at 975, 1000 , and $1005 \mathrm{~cm}^{-1}$ for $n=2-4$ are formed by the $2 n-$ $1 \mathrm{~V}=\mathrm{O}$ and $\mathrm{Ti}^{(-)}=\mathrm{O}$ stretching modes, in good agreement with the $975 \mathrm{~cm}^{-1}$ stretching modes of compounds with titanyl groups in solution [24] and with stretches of vanadyl groups in anionic $\left(\mathrm{V}_{2} \mathrm{O}_{5}\right)_{n}^{-}$[4] and neutral $\left(\mathrm{V}_{2} \mathrm{O}_{5}\right)_{n}$ (see below) clusters. The broad bands with maxima at $820 \mathrm{~cm}^{-1}\left(\mathrm{~V}_{3} \mathrm{TiO}_{10}^{-}\right), 880 \mathrm{~cm}^{-1}\left(\mathrm{~V}_{5} \mathrm{TiO}_{15}^{-}\right)$, and $885 \mathrm{~cm}^{-1}\left(\mathrm{~V}_{7} \mathrm{TiO}_{20}^{-}\right)$are due to the symmetric and antisymmetric stretches of the $M-\mathrm{O}-M$ bridges. The width of this band is considerably broader in the experimental spectra, similar to the IRMPD spectra of the larger vanadium oxide anions [4] and is tentatively attributed to pronounced intermode coupling, which is completely neglected within the harmonic approximation and therefore not well reproduced in the simulated spectra. Finally, the absorption below $800 \mathrm{~cm}^{-1}$ is due to vibration modes involving large parts of the cluster.

The singly substituted $\left(\mathrm{V}_{2} \mathrm{O}_{5}\right)_{n-1}\left(\mathrm{VTiO}_{5}\right)^{-}(n=2-4)$ cluster anions are isoelectronic with neutral $\left(\mathrm{V}_{2} \mathrm{O}_{5}\right)_{n}$ clusters. Because neutral clusters are experimentally difficult to mass select it is of interest to check if one can characterize the structure of neutral clusters by performing experiments on the corresponding mixed, isoelectronic cluster anions. The simulated IR spectra for $\left(\mathrm{V}_{2} \mathrm{O}_{5}\right)_{n}(n=2-4)$ are shown in Fig. 3. The calculated geometries are similar but of higher symmetry than the corresponding Ti-doped anions due to the presence of only one type of metal atoms. Indeed, the IR spectra are similar to the corresponding counterparts, supporting this indirect approach as an alternative method to probe the geometric structure of neutral clusters.

The IRMPD spectra of the more Ti-rich species $\mathrm{V}_{4-n} \mathrm{Ti}_{n} \mathrm{O}_{10}^{-}(n=2-4)$ are also shown in Fig. 2. The main fragmentation channel of $\mathrm{V}_{2} \mathrm{Ti}_{2} \mathrm{O}_{10}^{-}$is the formation of $\mathrm{VTi}_{2} \mathrm{O}_{7}^{-}$. $\mathrm{VTi}_{3} \mathrm{O}_{10}^{-}$and $\mathrm{Ti}_{4} \mathrm{O}_{10}^{-}$are oxygen richer and consequently the loss of molecular $\left(\mathrm{Ti}_{4} \mathrm{O}_{10}^{-}\right)$or atomic oxygen $\left(\mathrm{VTi}_{3} \mathrm{O}_{10}^{-}\right.$and $\left.\mathrm{Ti}_{4} \mathrm{O}_{10}^{-}\right)$is prominent. These observations are in line with collision induced dissociation experiments on vanadium oxide clusters with a high oxygen to metal ratio for which loss of weakly bound $\mathrm{O}_{2}$ and $\mathrm{O}$ species was reported [16].

Compared to the monotitanium species the spectra of more Ti-rich cluster anions $\mathrm{V}_{4-n} \mathrm{Ti}_{n} \mathrm{O}_{10}^{-}(n=2-4)$ are similar above $750 \mathrm{~cm}^{-1}$. All give a sharp band slightly below $1000 \mathrm{~cm}^{-1}$ and a broad and intense band around $780-850 \mathrm{~cm}^{-1}$. The vibrational structure below $750 \mathrm{~cm}^{-1}$ is richer than for the closed-shell systems.

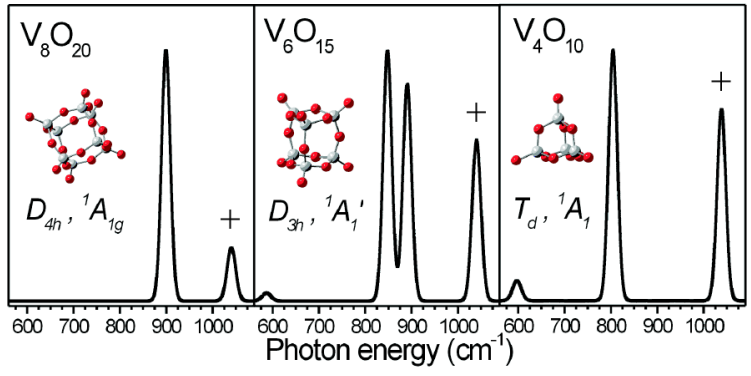

FIG. 3 (color online). Geometries and harmonic IR absorption of $\mathrm{V}_{4} \mathrm{O}_{10}, \mathrm{~V}_{6} \mathrm{O}_{15}$, and $\mathrm{V}_{8} \mathrm{O}_{20}$ obtained at the B3LYP/TZVP level. Stretches of the $\mathrm{V}=\mathrm{O}$ bonds are labeled with + . 
The most stable structures found computationally for $\mathrm{V}_{4-n} \mathrm{Ti}_{n} \mathrm{O}_{10}^{-}(n=1-4)$ all have a tetrahedral shape similar to the geometry of $\mathrm{V}_{4} \mathrm{O}_{10}$. Electronically these clusters are in an open shell state; doublet, triplet, and quartet for $\mathrm{V}_{2} \mathrm{Ti}_{2} \mathrm{O}_{10}^{-}, \mathrm{VTi}_{3} \mathrm{O}_{10}^{-}$, and $\mathrm{Ti}_{4} \mathrm{O}_{10}^{-}$, respectively. For each additional titanium atom there is a $(-\mathrm{O})_{3} \mathrm{Ti}-\mathrm{O} \cdot$ unit with a free radical localized on a singly titanium-bonded terminal oxygen atom, $\mathrm{O}$ - (i.e., three free radicals in $\left.\mathrm{Ti}_{4} \mathrm{O}_{10}^{-}\right)$. The length of the $\mathrm{Ti}^{(-)}=\mathrm{O}$ bond $(163 \mathrm{pm})$ is comparable to the $\mathrm{V}=\mathrm{O}$ bond $(159 \mathrm{pm})$ and significantly shorter than the weaker $\mathrm{Ti}-\mathrm{O} \cdot$ bond $(188 \mathrm{pm})$. The presence of multiple $\mathrm{Ti}-\mathrm{O}$. radical sites in $\mathrm{Ti}_{4} \mathrm{O}_{10}^{-}$is surprising because oxygen rich transition metal oxide species tend to form superoxo $\left(\mathrm{O}_{2}\right)^{-}$or peroxo $\left(\mathrm{O}_{2}\right)^{2-}$ units as observed for $\mathrm{V}_{2} \mathrm{O}_{6}^{+}$[6] and $\mathrm{V}_{2} \mathrm{O}_{7}^{-}$[25,26]. Indeed, a $\mathrm{Ti}_{4} \mathrm{O}_{10}^{-}$isomer with a superoxo ligand was found, but it is $0.52 \mathrm{eV}$ higher in energy. To couple the two $\mathrm{O}$ radicals into a superoxo species, the tetrahedral cage opens to a bridged ring structure and two threefold coordinated $\mathrm{O}=\mathrm{Ti}\left(\mathrm{O}^{-}\right)_{2}$ sites are created, while in the cage structure with the three radical sites, all four $\mathrm{Ti}$ are fourfold coordinated. The calculated IR spectrum (not shown) also is in less good agreement. The predicted band around $800 \mathrm{~cm}^{-1}$ shows a characteristic splitting that is not seen and the $\mathrm{Ti}=\mathrm{O}$ stretch bands are predicted to be more intense. Formation of two $\mathrm{W}-\mathrm{O} \cdot$ radical sites has also been shown for O-rich $\mathrm{WO}_{n}$ clusters [27].

Summarizing, the infrared spectroscopy of buffer gas cooled, mass-selected bimetallic oxide clusters has systematically been studied. By tuning the cluster composition we could change the number of valence electrons. Singly substituted $\left(\mathrm{V}_{2} \mathrm{O}_{5}\right)_{n-1}\left(\mathrm{VTiO}_{5}\right)^{-}(n=2-4)$ anions have structures similar to those of neutral, pure vanadium oxide clusters, and they are isoelectronic. $\mathrm{V}_{n-4} \mathrm{Ti}_{n} \mathrm{O}_{10}^{-}(n=1-4)$ cluster anions are shown to maintain a tetrahedral shape with increasing $n$, similar to $\mathrm{V}_{4} \mathrm{O}_{10}$, even though this leads to an increasing number of unpaired electrons. Our results show that IRMPD spectroscopy is also applicable to more complex clusters, which will prove useful for future investigations aimed at characterizing tailor-made model systems for adsorbate-support interactions in catalytic systems.

This work is supported by the Collaborative Research Center 546 of the Deutsche Forschungsgemeinschaft. The authors acknowledge the support of the Stichting voor Fundamenteel Onderzoek der Materie (FOM) in providing the required beam time on FELIX and highly appreciate the skillful assistance of the FELIX staff. E. J. and P.L. thank the Fonds voor Wetenschappelijk OnderzoekVlaanderen (FWO) for financial support.

*Electronic address: janssens@physik.fu-berlin.de †Electronic address: js@chemie.hu-berlin.de

ثElectronic address: asmis@fhi-berlin.mpg.de
[1] R. W. Siegel, E. Hu, M. C. Roco, Nanostructure Science and Technology: A Worldwide Study (National Science and Technology Council, Loyola College, Maryland, 1999), available from: http://itri.loyola.edu/nano/final/.

[2] D. K. Böhme and H. Schwarz, Angew. Chem., Int. Ed. Engl. 44, 2336 (2005).

[3] A. Fielicke, G. Meijer, and G. von Helden, J. Am. Chem. Soc. 125, 3659 (2003).

[4] K. R. Asmis, G. Santambrogio, M. Brümmer, and J. Sauer, Angew. Chem., Int. Ed. Engl. 44, 3122 (2005).

[5] K. R. Asmis, M. Brümmer, C. Kaposta, G. Santambrogio, G. von Helden, G. Meijer, K. Rademann, and L. Wöste, Phys. Chem. Chem. Phys. 4, 1101 (2002).

[6] K.R. Asmis, G. Meijer, M. Brümmer, C. Kaposta, G. Santambrogio, L. Wöste, and J. Sauer, J. Chem. Phys. 120, 6461 (2004).

[7] G. von Helden, A. Kirilyuk, D. van Heijnsbergen, B. Sartakov, M. A. Duncan, and G. Meijer, Chem. Phys. 262, 31 (2000).

[8] D. van Heijnsbergen, G. von Helden, G. Meijer, and M. A. Duncan, J. Chem. Phys. 116, 2400 (2002).

[9] K. Demyk, D. van Heijnsbergen, G. von Helden, and G. Meijer, Astron. Astrophys. 420, 547 (2004).

[10] S. F. Vyboishchikov and J. Sauer, J. Phys. Chem. A 105, 8588 (2001).

[11] W. Bouwen, P. Thoen, F. Vanhoutte, S. Bouckaert, F. Despa, H. Weidele, R. E. Silverans, and P. Lievens, Rev. Sci. Instrum. 71, 54 (2000).

[12] E. Janssens, H. Tanaka, S. Neukermans, R. E. Silverans, and P. Lievens, Phys. Rev. B 69, 085402 (2004).

[13] D. Oepts, A. F. G. van der Meer, and P. W. van Amersfoort, Infrared Phys. Technol. 36, 297 (1995).

[14] J. Oomens, A. G. G. M. Tielens, B. G. Sartakov, G. von Helden, and G. Meijer, Astrophys. J. 591, 968 (2003).

[15] H. Wu and L. S. Wang, J. Chem. Phys. 107, 8221 (1997).

[16] R.C. Bell, K. A. Zemski, D. R. Justes, and A.W. Castleman, Jr., J. Chem. Phys. 114, 798 (2001).

[17] Y. Matsuda and E. R. Bernstein, J. Phys. Chem. A 109, 314 (2005).

[18] M. Foltin, G. J. Stueber, and E. R. Bernstein, J. Chem. Phys. 111, 9577 (1999).

[19] See EPAPS Document No. E-PRLTAO-96-060625 for an analysis of the mass spectra of the mixed vanadiumtitanium oxide cluster anions. For more information on EPAPS, see http://www.aip.org/pubservs/epaps.html.

[20] R. Ahlrichs, M. Bär, M. Haser, H. Horn, and C. Kölmel, Chem. Phys. Lett. 162, 165 (1989).

[21] A. D. Becke, Phys. Rev. A 38, 3098 (1988).

[22] A. Schäfer, C. Huber, and R. Ahlrichs, J. Chem. Phys. 100, 5829 (1994).

[23] P. Deglmann, F. Furche, and R. Ahlrichs, Chem. Phys. Lett. 362, 511 (2002).

[24] P. Comba and A. Merbach, Inorg. Chem. 26, 1315 (1987).

[25] H. J. Zhai and L. S. Wang, J. Chem. Phys. 117, 7882 (2002).

[26] S. F. Vyboishchikov and J. Sauer, J. Phys. Chem. A 104, 10913 (2000).

[27] H. J. Zhai, B. Kiran, L. F. Cui, X. Li, D. A. Dixon, and L. S. Wang, J. Am. Chem. Soc. 126, 16134 (2004). 